\title{
Simulación clínica y Jean Baudrillard
}

\author{
Clinical simulation and Jean Baudrillard
}

\author{
Eduardo Herrera-Aliaga*
}

\section{Estimada Editora:}

$\mathrm{E}^{\prime}$ mundo de la educación en ciencias de la salud ha visto surgir el explosivo auge de la simulación clínica como metodología de enseñanza-aprendizaje. ${ }^{1}$ Esta metodología se inserta, en la actualidad, en la mayoría de los currículos de las carreras del área; también, se ha utilizado en el postgrado y en la recertificación de competencias de los profesionales que ya están inmersos en el mundo laboral. ${ }^{2}$

En comunicaciones previas y en diversos medios se han reportado tanto los beneficios de la simulación como sus limitaciones. ${ }^{2-7}$ Hoy en día, no concebimos una metodología que ofrezca, con la misma fuerza, el potencial de desarrollo que posee la simulación. Aún existen pendientes en cuanto a investigar varios aspectos, por ejemplo, el impacto que la simulación posee sobre la atención del paciente; $;^{1,2,7} \sin$ embargo, es posible mencionar que el camino ya se ha iniciado y por tanto, como siempre sucede en ciencia, aparecerán nuevas preguntas.

La idea central de la presente comunicación es exponer una fusión entre las ideas de Jean Baudrillard (1929-2007) y la simulación clínica, conjunción que no ha sido contemplada ni tratada previamente.

Si bien la simulación surge masivamente en la aviación, ${ }^{8}$ es Baudrillard quien expone ampliamente sus bases filosóficas. Explica cómo las tecnologías llegan a "engañar" la consciencia, haciendo difícil distinguir, desde el punto de vista de la percepción humana, lo que es real versus lo que no lo es. ${ }^{9}$ Baudrillard, visionario de lo postmoderno, explica que la simulación existe gracias a que es posible reemplazar lo que es característico de un fenómeno (el "signo"); por tanto, si este fenómeno se puede simular, se está suplantando la realidad, que a ojos de quien la percibe puede hacer imposible la distinción entre lo real y lo simulado.9-11 Entonces, gracias a lo anterior, es posible la recreación de escenarios de simulación, los cuales surgen de lo real-por ejemplo, una experiencia médica o un caso clínico-; de este modo, un actor (o paciente simulado) o un simulador de cuerpo completo (maniquí) puede simular signos y síntomas, y hacer parecer real una situación. Es importante comprender lo anterior, ya que un buen nivel de realismo de la simulación (fidelidad) puede lograrse con adecuadas planificaciones y guiones. En una fase posterior al escenario de simulación se reflexiona en torno a la experiencia vivida-debriefing-, ${ }^{12,13}$ donde se reconstruye lo vivenciado.

Finalmente, resultaría interesante poder abrir el debate en relación con lo que actualmente se realiza en simulación y poder conectar estas ideas con lo expuesto por Baudrillard, donde el reemplazo del "signo", la realidad y el simulacro son transversales en su obra.

\section{REFERENCIAS}

1. Chiniara G, Cole G, Brisbin K, Huffman D, Cragg B, Lamacchia $M$, et al. Simulation in healthcare: a taxonomy and a conceptual framework for instructional design and media selection. Medical Teacher. 2013; 35: e1380-e1395.

2. Corvetto M, Bravo M, Montaña R, Utili F, Escudero E, Boza C, et al. Simulación en educación médica: una sinopsis. Rev Méd Chile. 2013; 141 (1): 70-79.

3. Rojas A, Borja H. ¿Es ética la utilización de técnicas de simulación en la docencia médica de pregrado? Reflexión bioética. Rev Chil Enferm Respir. 2016; 32 (1): 34-37.

4. Kerrigan N. Simulación, zuna necesidad en el entrenamiento para la cirugía laparoscópica colorrectal? Rev Chil Cir. 2017; 69 (6): 508-512.

5. Alvarado J, Henríquez J, Castillo R, Sosa J, León F, Varas J, et al. Programa pionero de simulación en sutura para estudiantes de medicina de pregrado. Rev Chil Cir. 2015; 67 (5): 480-485. 
6. Moya P, Ruz M, Parraguez E, Carreño V, Rodríguez A, Froes $P$. Efectividad de la simulación en la educación médica desde la perspectiva de seguridad de pacientes. Rev Méd Chile. 2017; 145 (4): 514-526.

7. Cook D, Hatala R, Brydges R, Zendejas B, Szostek J, Wang A, et al. Technology-enhanced simulation for health professions education a systematic review and meta-analysis. JAMA. 2011; 306 (9): 978-988.

8. Rosen K. The history of medical simulation. J Crit Care. 2008; 23: 157-166.

9. von Werder S. ¿Ficción o hiperrealidad?: un estudio comparado de los relatos "Tlön, Uqbar, Orbis Tertius?", de Jorge Luis Borges y "La Salida?", de Daniel Kehlmann. Literatura y Lingüística. 2013; (28): 107-121.

10. Vaskes I. La transestética de Baudrillard: simulacro y arte en la época de simulación total. Estudios de Filosofía. 2008; (38): 197-219.

11. Baudrillard J. Cultura y simulacro. Barcelona: Editorial Kairos; 1977.
12. Rudolph J, Simon R, Dufresne R, Raemer D. There's no such thing as "nonjudgmental" debriefing: a theory and method for debriefing with good judgment. Simul Healthcare. 2006; 1: 49-55.

13. Fanning R, Gaba D. The role of debriefing in simulation-based learning. Simul Healthcare. 2007; 2 (1): 1-11.

\section{Correspondencia:}

\section{Eduardo Herrera-Aliaga}

Centro de Simulación Clínica y

Laboratorios, Facultad de Salud,

Universidad Bernardo O’Higgins

General Gana 1702, Santiago, Chile.

Tel: +562-2477-2275

E-mail: eduardo.herrera@ubo.cl 